\title{
Transcranial direct current stimulation and repetitive transcranial magnetic stimulation in consultation-liaison psychiatry
}

\author{
L.C.L. Valiengo ${ }^{1,2}$, I.M. Benseñor ${ }^{1,2}$, P.A. Lotufo ${ }^{1,2}$, R. Fraguas Jr. ${ }^{1,2}$ and A.R. Brunoni ${ }^{1,2}$ \\ ${ }^{1}$ Centro de Pesquisas Clínicas, Hospital Universitário, Universidade de São Paulo, São Paulo, SP, Brasil \\ ${ }^{2}$ Instituto de Psiquiatria, Hospital das Clínicas, Faculdade de Medicina, Universidade de São Paulo, São Paulo, SP, Brasil
}

\begin{abstract}
Patients with clinical diseases often present psychiatric conditions whose pharmacological treatment is hampered due to hazardous interactions with the clinical treatment and/or disease. This is particularly relevant for major depressive disorder, the most common psychiatric disorder in the general hospital. In this context, nonpharmacological interventions could be useful therapies; and, among those, noninvasive brain stimulation (NIBS) might be an interesting option. The main methods of NIBS are repetitive transcranial magnetic stimulation (rTMS), which was recently approved as a nonresearch treatment for some psychiatric conditions, and transcranial direct current stimulation (tDCS), a technique that is currently limited to research scenarios but has shown promising results. Therefore, our aim was to review the main medical conditions associated with high depression rates, the main obstacles for depression treatment, and whether these therapies could be a useful intervention for such conditions. We found that depression is an important and prevalent comorbidity in a variety of diseases such as epilepsy, stroke, Parkinson's disease, myocardial infarction, cancer, and in other conditions such as pregnancy and in patients without enteral access. We found that treatment of depression is often suboptimal within the above contexts and that rTMS and tDCS therapies have been insufficiently appraised. We discuss whether rTMS and tDCS could have a significant impact in treating depression that develops within a clinical context, considering its unique characteristics such as the absence of pharmacological interactions, the use of a nonenteral route, and as an augmentation therapy for antidepressants.
\end{abstract}

Key words: Neuromodulation; Liaison; Major depressive disorder; Transcranial stimulation

\section{Introduction}

Patients admitted to the general hospital ward often present psychological complaints regardless of the reason for their hospitalization (1). The causes for the association of medical with psychological symptoms range from acute psychological reactions (e.g., anxiety, denial, fear in a sickness context) to overt psychiatric symptoms (e.g., "lupus psychosis") caused by a medical condition. In many situations, however, the psychiatric condition develops after, and in parallel with the medical illness. In this scenario, not only the clinical but also the psychiatric condition should be treated. Considering the aging of the population and the development of treatments and interventions that have extended survival rates for many conditions (e.g., myocardial infarction, cancer, HIV(AIDS), this is the most common scenario for consultation-liaison psychiatry at the present time (2).

In this regard, "secondary depression" is the most prevalent psychiatric disorder due to a general medical condition that is diagnosed in patients with primary neurologic, oncologic, autoimmune, infectious, and painful diseases (2). In most cases, the treatment is similar to that of major depressive disorder (MDD), and in fact, antidepressant drugs can significantly improve the depressive symptoms of medical conditions (3). However, it is also true that, for such patients, the antidepressants interact with the medical treatment, increasing the rate of adverse effects (3). In addition, specific classes of antidepressants are forbidden in certain contexts because of the likelihood of hazardous interactions with the medical treatment (4). Finally, antidepressants per se can cause side effects that are similar to those of the illness (4). As a result, depression in medical illness is still an undertreated condition in which the efficacy of antidepressants is hindered for multiple reasons such as more overt side effects and restrictions for specific antidepressant classes and titration to increase the dose compared to primary depression.

Correspondence: L.C.L. Valiengo, Centro de Pesquisas Clínicas, Hospital Universitário, USP, Av. Prof. Lineu Prestes, 2565, 3oandar, 05508-000 São Paulo, SP, Brasil. E-mail: valiengo@usp.br

Received April 6, 2013. Accepted July 15, 2013. First published online October 2, 2013. 
In this context, nonpharmacological interventions might be useful and, in fact, different forms of psychotherapy, such as interpersonal, cognitive-behavior, or brief, are effective interventions for depression (5). On the other hand, psychotherapy requires trained healthcare providers and an active engagement by the patients, which are circumstances that are not always available. Moreover, psychotherapy is more effective in patients with mild or moderate depression (5). Another nonpharmacological intervention that has gained attention in recent years is noninvasive brain stimulation, which is represented by two main techniques, described below.

\section{Repetitive transcranial magnetic stimulation (rTMS)}

Transcranial magnetic stimulation (TMS) depolarizes neurons through a potent, relatively focal, electromagnetic field that is generated beneath a coil positioned over the patient's scalp. The electric depolarization induced is strong enough to trigger action potentials (6). When applied repetitively, rTMS induces not only neuromodulatory changes, but also neuroplasticity in the targeted area. It is known that high-frequency stimulation $(>10 \mathrm{~Hz})$ can increase the excitability of the target cortex and low-frequency stimulation $(<1 \mathrm{~Hz})$ can decrease the excitability of that area (7). Over the past 20 years, more than 50 randomized, sham-controlled trials have investigated the antidepressant effects of rTMS (i.e., excitatory effects), showing that it is effective in the treatment of MDD (8). In fact, rTMS was recently approved by several international regulatory agencies as a clinical (not experimental) treatment for MDD. The most used target to treat depression with rTMS consists of high-frequency stimulation of the left dorsolateral prefrontal cortex (DLPFC) (8). Generally, the patient receives from 10 to 20 sessions of rTMS, with resulting long-term benefits (9).

\section{Transcranial direct current stimulation (tDCS)}

In contrast with TMS, tDCS is based on the application of weak (0.5-2 mA), direct electric current to the brain through relatively large electrodes placed on the scalp (10). One electrode is necessarily placed over the scalp, above the cortical area to be stimulated. The other electrode can also be positioned over the scalp, or, alternatively, over an extracephalic position (e.g., the deltoid muscle). One electrode is the anode and the other is the cathode. The first is responsible for stimulation of the chosen area and the latter for inhibition of the chosen area. A direct electric current flows from the anode to the cathode. During tDCS, the cortical areas close to the anode are hypopolarized, and those close to the cathode are hyperpolarized, leading to an increase or a decrease, respectively, in cortical excitability). One important difference of tDCS compared to rTMS is that the former does not trigger action potentials, but rather modulates spontaneous neuronal network activity (11). This occurs because the membrane potentials are changed by only a few millivolts during tDCS, which is much lower than the necessary threshold for eliciting action potentials (11). For MDD, the anode is placed over the area corresponding to the left DLPFC and the cathode, either over the right DLPFC or left supraorbital region (6). Generally, each patient receives from 10 to 20 sessions of about $20 \mathrm{~min}$ each (12). The current is usually 1-2 mA (12).

tDCS is still considered an investigational intervention, although encouraging results from prior trials (13) and data from our group (14) suggest that it might be incorporated in the therapeutic arsenal for MDD in the near future. Therefore, the aim of this comprehensive review is to address the main medical conditions in which MDD occurs, assessing the efficacy of noninvasive brain stimulation.

\section{Methods}

Our first step was choosing the medical conditions that would be assessed in this review. For this goal, we reviewed consultation-liaison psychiatry articles describing the medical specialties that present high depression rates $(1,15)$. We also assessed recent textbooks on general psychiatry, consultation-liaison psychiatry, and psychosomatic medicine $(2,16)$. After that, we summarized and described the main medical conditions for which depression treatment is challenging because of either its high rate of occurrence or specific contraindications.

The second step was assessing the main challenges for treating depression in each reviewed disease or group of diseases. After that, we determined whether there were studies on noninvasive brain stimulation for these disorders. Finally, considering the bulk of reviewed evidence, we discuss the potential advantages and disadvantages of using these nonpharmacological therapies for treating depression in a clinical context.

\section{Results}

\section{Cardiology}

Myocardial infarction (MI). Rates of depression post-MI are high, with $20-30 \%$ of patients presenting major depression (17). Post-MI depression is associated with a 4-fold increased risk of mortality, an effect that is observed for at least 18 months (18). Several mechanisms have been proposed to explain such increased mortality risk, e.g., increased catecholamine levels, decreased heart rate variability (19), and poor compliance with a healthy lifestyle and dietary habits (20).

Despite the high prevalence of post-MI depression, only $10 \%$ of cases are adequately diagnosed and treated (21). The use of antidepressants also has some limitations. Tricyclics and monoamine oxidase inhibitors have a variety of adverse effects that can hinder adequate treatment, e.g., anticholinergic effects, arrhythmias, orthostatic hypotension, and tachycardia. Conversely, novel antidepressants 
such as the selective serotonin reuptake inhibitors (SSRIs), serotonin-norepinephrine reuptake inhibitors (SNRIs), mirtazapine, and bupropion do not present these effects $(22,23)$. However, SSRIs interact with cytochrome P450, an issue that can limit their use, since cardiac patients often use several drugs (24). Non-SSRI antidepressants, however, might also be limited. For example, mirtazapine might induce weight gain (25), and venlafaxine can increase blood pressure levels (26). We found only one rTMS case report evaluating post-MI depression, in which the left DLPFC was stimulated for the treatment of a 55year-old man with depression and panic disorder 6 months after MI (27). Two sessions of rTMS were performed daily for 3 weeks, and the condition of the patient improved more than $50 \%$ on the Hamilton Depression Rating Scale.

Chronic heart failure (CHF). The incidence of CHF is increasing worldwide and is associated with high mortality (28). The prevalence of depression associated with $\mathrm{CHF}$ ranges from 13 to $77 \%$ (29). Like $\mathrm{MI}$, depression associated with CHF increases mortality (30). There are some mechanisms that account for the association between these two conditions. One is that depression can hyperactivate the hypothalamic-pituitary-adrenal axis, leading to an increase in blood cortisol levels and, worsening CHF with increased sympathetic activity (31).

Also, in cases of CHF, depression is often underdiagnosed, possibly due to the co-occurrence of similar symptoms in both conditions such as fatigue, loss of energy, cognitive complaints, weight alterations, and sleep disorders (32).

Antidepressant therapy in $\mathrm{CHF}$ has the same issues as that for $\mathrm{MI}$, since $\mathrm{CHF}$ itself requires treatment with several drugs, many of which interact with cytochrome P450. At the present time, the treatment for depression associated with CHF is mainly limited to SSRIs, with a few controlled studies showing evidence for sertraline, paroxetine, and fluoxetine (32).

\section{Respiratory diseases}

Chronic obstructive pulmonary disease (COPD). The prevalence of depression in COPD is about $10-40 \%$ (33). The prevalence of depression increases with the severity of COPD, being 2.5 times higher in severe COPD patients (34). The association of both conditions leads to more COPD exacerbations, more hospital readmissions, and an increase in mortality (35). These factors can be explained by the poor adherence of depressed patients to medical recommendations (36). Another possible explanation is the significant association between smoking and mental disorders (37). One hypothesis to account for the high prevalence of depression in COPD is that chronic hypoxia could lead to a decrease in production of monoamines like dopamine and noradrenaline, and this predisposes to depression (38). One psychosocial reason would be the loss of independence and self-confidence in these patients (39).
As occurs with other chronic conditions, only $44 \%$ of COPD patients with depression are diagnosed correctly (40). One possible reason is the association of some symptoms in both conditions such as loss of energy, sleep disturbance, and weight loss. Treatment with antidepressants also has some concerns. Sedative psychotropic drugs (e.g., tricyclic antidepressants such as mirtazapine) can worsen COPD symptoms, as they might decrease activity in the respiratory center during sleep (41).

\section{Oncology}

Although almost all types of cancer have high rates of depression, two of them are particularly important: pancreatic (because of a high depression incidence) and breast (because of its high prevalence) $(42,43)$.

In fact, depression also precedes pancreatic cancer more than four times more often than with other malignancies (44). According to a recent study, almost $80 \%$ of patients with pancreatic cancer present depression, which is more than other gastrointestinal malignancies such as liver (60\%), esophageal (24\%), gastric (36\%), and colorectal $(20 \%)$ cancer (45). The depressive symptoms are usually treated with tricyclic antidepressants that are also advantageous for controlling pain symptoms and with SSRIs (46); although side effects associated with these antidepressants might limit proper treatment.

Almost 1 of 4 women with breast cancer develops depression (47). Importantly, tamoxifen - an agent that has antiestrogenic properties in the breast - is used for treatment of women with estrogen receptor positive tumors to decrease the risk of recurrence or the development of a new primary tumor. This drug is metabolized by CYP2D6 to endoxifen, its active form. SSRI antidepressants, however, also act on CYP2D6, and therefore the use of this drug class in women taking tamoxifen is contraindicated. In fact, buproprion and other common antidepressants also act on CYP2D6, limiting the therapeutic arsenal of treatment of depression in these patients mainly to venlafaxine and desvenlafaxine (48).

\section{Neurology}

Stroke. Stroke is associated with depression in 5-72\% of patients (49). Post-stroke depression is associated with increased morbidity and mortality (49). In addition, poststroke depression treatment leads to an increase in the probability of 6-year survival (50). Some studies showed positive results of treatment with citalopram (51), but there were very frequent adverse effects. The stroke randomized trials by Kim et al. (52) and Jorge et al. (53) enrolled 18 and 20 patients, respectively, using rTMS over the left DLPFC. Both observed improvement of depression symptoms. Bueno et al. (54) described a patient with post-stroke depression with marked improvement of depressive symptoms after a 10-day course of tDCS. 
Epilepsy. Depression is the most frequent psychiatric condition associated with epilepsy (55). Almost half of the patients with epilepsy present depression (56). Rates of suicide in patients with epilepsy and depression are four to five times higher than those in the general population (57). Poor control of seizures, complex partial seizures, and temporal lobe epilepsy are risk factors for depression (58).

Despite its high prevalence, MDD is underdiagnosed and undertreated in patients with epilepsy (56). An issue regarding pharmacological treatment of these patients is the important interaction between anticonvulsants and antidepressants. Some antidepressant drugs (bupropion, clomipramine) can decrease the seizure threshold and increase the risk of seizures (59). The most used antidepressants in this group of patients are the SSRIs.

Parkinson's disease (PD). The prevalence of depression in PD is about $50 \%$ (60). Difficulty in diagnosing depression in $P D$ is probably due to overlapping symptoms between the two conditions such as psychomotor retardation, cognitive deficits, fatigue, decreased energy, appetite changes, and physical complaints (2). Pharmacological treatment in this group of patients involves dopaminergic medication and antidepressants. Regarding the former, pramipexole is the most studied, with a meta-analysis showing positive results (61). Other medications used for PD include catechol-O-methyl transferase (COMT) inhibitors and monoamine oxidase B inhibitors (62). Antidepressants include tricyclics, trazodone, SSRIs, SNRIs, and mirtazapine (2).

Side effects should be taken into consideration, due to the probability of interactions with other drugs, particularly those that are metabolized by cytochrome P450. The evidence for antidepressants is insufficient, with two systematic reviews being inconclusive (63). Tricyclics can improve sleep and ameliorate some PD symptoms by their anticholinergic actions (2). However, elderly PD patients are at a greater risk for the following adverse effects of tricyclics: delirium, hypotension, and urinary retention (60).

We found five studies using rTMS for the treatment of depression in PD. Two were randomized clinical trials (RCTs) and three were open trials (64-66). Fregni et al. (67) evaluated 42 patients using high-frequency rTMS over the DLPFC. They found an improvement of $38 \%$ in the rTMS group and $41 \%$ in the fluoxetine group. On the other hand, Pal et al. (68) studied 22 patients, also using high-frequency rTMS, and found a $26 \%$ improvement in the group using rTMS vs $<1 \%$ in the sham group. The open trials used rTMS, and all showed improvement of depression (64-66). Two $(64,66)$ of them used highfrequency rTMS on the left DLPFC, and Dragasevic et al. (65) used low-frequency rTMS on prefrontal cortex bilaterally. While the first two studies had a high percentage of improvement of depression, the last one had only a moderate effect.

\section{Infectious diseases}

HIV. The prevalence of depression in patients with HIV is around $36 \%$ (69). There is an association between depression and alterations in the immune system (70). Also, there is a direct correlation between viral load and depression in women and an inverse correlation between the number of natural killer (NK) cells and depression (71). As discussed, most antidepressants are metabolized by cytochrome P450, and several anti-HIV drugs (e.g., ritonavir, indinavir, protease inhibitors) inhibit its metabolism (72). Because of these issues, treatment of depression in HIV patients is often a challenge since even small doses of antidepressants can lead to important adverse effects (2).

Knotkova et al. (73) studied the use of tDCS in patients with HIV and depression. They administered 10 sessions of tDCS for $20 \mathrm{~min}$ at $2 \mathrm{~mA}$ at each visit. The electrodes were placed over the DLPFC in the $\mathrm{F} 3$ position for anodal stimulation and the contralateral supraorbital region for cathodal stimulation. The authors found a substantial improvement of depression. In the same study, a nonrandomized trial was performed with 10 patients with HIV and depression, also after a 10-day course of tDCS, and there was improvement of depressive symptoms.

\section{Antenatal and postnatal depression}

Perinatal depression is a common condition, with a prevalence of $15-22 \%$ (74). Some depressive symptoms such as lack of appetite, pessimistic thoughts, and insufficient self-care can be especially hazardous during pregnancy, affecting both the mother and the fetus. The treatment of antenatal depression is challenging since some antidepressant drugs have been associated with birth defects, e.g., paroxetine (75), sertraline (75), citalopram (76), and fluoxetine (76). In addition, several antidepressant drugs are not recommended for postnatal depression - some examples include SSRIs, venlafaxine, and lithium (77).

Four studies (78-81) with rTMS and tDCS in antenatal depression were found, all of them using rTMS. The study by Kim et al. (78) was an open trial in which 10 women were treated with low frequency over the right DLPFC and showed a $70 \%$ response rate. The remaining three studies were case reports, all with antidepressant effects of high-frequency rTMS over the left DLPFC (7981). We found that only one study by Garcia et al. (82) using $10 \mathrm{~Hz}$ rTMS over the left DLPFC to treat postpartum depression in 9 women showed a significant reduction in depressive symptoms by the end of the second week of treatment.

\section{Patients without enteral access}

Inpatients might present conditions that temporarily or 
permanently prevent them from taking oral medicines. Such conditions include upper gastrointestinal, pharyngeal, and head and neck tumors, sequelae of traumatic accidents, and neurologic conditions. In such cases the prevalence of depression might be even higher than in the general population, and proper treatment is hindered due to the lack of an oral route for antidepressants.

\section{rTMS and tDCS trials}

We identified some studies using rTMS and tDCS to treat depression associated with medical conditions (Table 1). Most of them were nonrandomized trials and case reports, although we found 4 RCTs - 2 in stroke patients and 2 in PD. We described them earlier under the respective associated medical condition.

We did not find studies using neuromodulation to treat depression in other disorders such as cancer, epilepsy, COPD, arrhythmias, and $\mathrm{CHF}$, and in patients without enteral access.

Only two studies used tDCS to treat secondary depression: Bueno et al. (54) and Knotkova et al. (73), both described earlier.

\section{Discussion}

We reviewed the medical conditions that are particularly associated with depression. In almost all scenarios, the use of antidepressants for the treatment of depression has important restrictions. This occurs due to two main aspects of antidepressant drugs: a) as reviewed, most of them are metabolized by cytochrome P450 enzymes, thus leading to interaction with drugs used for the treatment of medical conditions; and b) the adverse effects can exacerbate symptoms of physical illness, increasing discontinuation rates.

All studies described improvement of depression, with few adverse effects reported. The most used technique of neuromodulation used was rTMS (13 of 15). Except for one study (65), all used the DLPFC as a target for neuromodulation, with all studies over the left DLPFC,

Table 1. Clinical studies of noninvasive brain stimulation in secondary depression.

\begin{tabular}{|c|c|c|c|c|c|c|}
\hline Disease/Reference & Technique & Design & Sample & $\begin{array}{l}\text { Duration } \\
\text { (days) }\end{array}$ & Position & Results \\
\hline \multicolumn{7}{|l|}{ Parkinson's } \\
\hline Pal et al. (68) & TMS & $\mathrm{RCT}$ & 22 & 10 & left DLPFC & Active was superior to sham \\
\hline Fregni et al. (67) & TMS & $\mathrm{RCT}$ & 42 & 10 & left DLPFC & $\begin{array}{l}\text { TMS had the same antidepressant } \\
\text { efficacy as fluoxetine }\end{array}$ \\
\hline Epstein et al. (64) & TMS & OT & 14 & 10 & left DLPFC & $\begin{array}{l}\text { High improvement in depression } \\
\text { symptoms }\end{array}$ \\
\hline Kormos (66) & TMS & OT & 7 & 10 & left DLPFC & $\begin{array}{l}6 \text { of } 7 \text { patients were responders at } \\
2 \text { weeks }\end{array}$ \\
\hline Dragasevic et al. (65) & TMS & OT & 10 & 10 & PFC & $\begin{array}{l}\text { Moderate but significant decrease } \\
\text { in scores of depression }\end{array}$ \\
\hline \multicolumn{7}{|l|}{ Stroke } \\
\hline Bueno et al. (54) & tDCS & Report & 1 & 10 & left DLPFC & $\begin{array}{l}\text { Marked improvement of depressive } \\
\text { symptoms }\end{array}$ \\
\hline Kim et al. (52) & TMS & $\mathrm{RCT}$ & 18 & 10 & left DLPFC & $\begin{array}{l}\text { Significant decrease in scores of } \\
\text { depression }\end{array}$ \\
\hline Jorge et al. (53) & TMS & $\mathrm{RCT}$ & 20 & 10 & left DLPFC & $\begin{array}{l}\text { Significant improvement of depressive } \\
\text { symptoms }\end{array}$ \\
\hline \multicolumn{7}{|r|}{ 然 } \\
\hline Knotkova et al. (73) & tDCS & OT & 10 & 10 & left DLPFC & Depression scores significantly decreased \\
\hline \multicolumn{7}{|l|}{ Postpartum } \\
\hline Garcia et al. (82) & TMS & OT & 9 & 20 & left DLPFC & Moderate effect-sizes at 2 weeks \\
\hline Kim et al. (78) & TMS & OT & 10 & 20 & right DLPFC & $\begin{array}{l}\text { Improvement of } 70 \% \text { on depressive } \\
\text { symptoms }\end{array}$ \\
\hline \multicolumn{7}{|l|}{ Pregnancy } \\
\hline Zhang et al. (79) & TMS & Report & 1 & 14 & left DLPFC & $\begin{array}{l}\text { Euthymic at the end of treatment but } \\
\text { with relapse } 2 \text { months later }\end{array}$ \\
\hline Tan et al. (80) & TMS & Report & 1 & - & left DLPFC & Remission of symptoms \\
\hline Nahas et al. (81) & TMS & Report & 1 & 5 & left DLPFC & Remission of symptoms \\
\hline \multicolumn{7}{|r|}{ 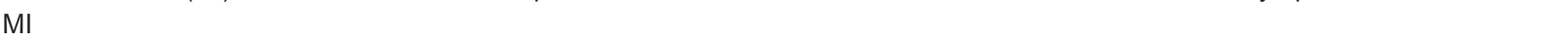 } \\
\hline Sakkas et al. (27) & TMS & Report & 1 & 21 & left DLPFC & Remission of symptoms \\
\hline
\end{tabular}

TMS: transcranial magnetic stimulation; tDCS: transcranial direct current stimulation; RCT: randomized clinical trial; OT: open trial; DLPFC: dorsolateral prefrontal cortex; PFC: prefrontal cortex; MI: myocardial infarction. 
except for one, which stimulated the right DLPFC (78).

The greatest advantages of methods of noninvasive stimulation for the treatment of depression associated with physical illness are that they overcome the difficulties resulting from pharmacokinetic interactions, the possibility of being given in association with SSRIs for augmentation of treatment, and the possibility of treatment of patients without enteral access.

The adverse effects associated with both rTMS and tDCS are minimal and short lived. Side effects of rTMS consist of transient headache, hearing changes and, rarely, seizures. Neurological patients with chronic headache could therefore be a concern, but studies have shown no increase in pain in such patients, because the headache is usually self-limiting. Also, one review article showed that rTMS is safe for migraine patients (83). Another possible concern is using rTMS in epilepsy. Studies have shown the safety of this technique in epilepsy using low-frequency rTMS. In addition, even the use of high-frequency rTMS as a noninvasive procedure did not activate epileptogenic foci, with the exception of a minority of patients with progressive myoclonic epilepsy (84). Therefore, with few and selflimited adverse effects, TMS and tDCS can be alternatives for use in medical conditions associated with depression. Importantly, the efficacy of rTMS in depression has been confirmed in randomized clinical trials and supported by meta-analysis, with moderately greater effectiveness in favor of active TMS $(85,86)$. For tDCS, one meta-analysis and one large clinical trial showed positive results $(13,14)$ for it as a promising therapeutic intervention in the future. One of these studies used a

\section{References}

1. Christodoulou C, Fineti K, Douzenis A, Moussas G, Michopoulos I, Lykouras L. Transfers to psychiatry through the consultation-liaison psychiatry service: 11 years of experience. Ann Gen Psychiatry 2008; 7: 10, doi: 10.1186/ 1744-859X-7-10.

2. Stern TA. Massachusetts General Hospital handbook of general hospital psychiatry. 6th edn. Philadelphia: Saunders/Elsevier; 2010.

3. Taylor D, Meader N, Bird V, Pilling S, Creed F, Goldberg D. Pharmacological interventions for people with depression and chronic physical health problems: systematic review and meta-analyses of safety and efficacy. $\mathrm{Br} J$ Psychiatry 2011; 198: 179-188, doi: 10.1192/bjp.bp.110.077610.

4. Hoppe C, Elger CE. Depression in epilepsy: a critical review from a clinical perspective. Nat Rev Neurol 2011; 7: 462472, doi: 10.1038/nrneurol.2011.104.

5. Jakobsen JC, Hansen JL, Simonsen S, Simonsen E, Gluud C. Effects of cognitive therapy versus interpersonal psychotherapy in patients with major depressive disorder: a systematic review of randomized clinical trials with metaanalyses and trial sequential analyses. Psychol Med 2012; 42: 1343-1357, doi: 10.1017/S0033291711002236. factorial design, randomizing 120 patients with depression into four groups: active tDCS with sertraline, sham tDCS with sertraline, active tDCS with oral placebo, and sham tDCS with oral placebo (14). Groups using active tDCS in monotherapy or combined with sertraline presented greater improvement of depression, with the combined treatment group showing the highest rates of improvement. This can be useful in clinical patients, because in some cases the dose of antidepressants might not be titrated upward due to adverse effects or interactions with other drugs. In such cases, tDCS augmentation could be an interesting option.

Another advantage of the use of tDCS in these groups of patients could be the relative low cost compared with rTMS (87) and the possibility of its use in primary health care. Because the device is portable, affordable, and easy-to-use, it could be easily adapted for application in primary care units.

To conclude, rTMS and tDCS have some unique characteristics that position them as interesting alternatives for the treatment of mental illnesses associated with organic diseases. Examples of these characteristics are less adverse effects and antidepressant effects of similar magnitude to antidepressant drugs. Another observation is that some conditions can benefit from TMS or tDCS. Noninvasive brain stimulation interventions can be a suitable option for patients having difficulties adhering to therapy, particularly those who present comorbidities, the elderly, and those on multiple medications. Future RCTs are necessary to evaluate the role of rTMS and tDCS in the treatment of depression associated with medical conditions.

6. Brunoni AR, Teng CT, Correa C, Imamura M, Brasil-Neto JP, Boechat R, et al. Neuromodulation approaches for the treatment of major depression: challenges and recommendations from a working group meeting. Arq Neuropsiquiatr 2010; 68: 433-451, doi: 10.1590/S0004-282X2010000300021.

7. Janicak PG, Nahas Z, Lisanby SH, Solvason HB, Sampson SM, McDonald WM, et al. Durability of clinical benefit with transcranial magnetic stimulation (TMS) in the treatment of pharmacoresistant major depression: assessment of relapse during a 6-month, multisite, open-label study. Brain Stimul 2010; 3: 187-199, doi: 10.1016/j.brs.2010.07.003.

8. Schutter DJ. Antidepressant efficacy of high-frequency transcranial magnetic stimulation over the left dorsolateral prefrontal cortex in double-blind sham-controlled designs: a meta-analysis. Psychol Med 2009; 39: 65-75, doi: 10.1017/ S0033291708003462

9. Fitzgerald PB, Brown TL, Marston NA, Daskalakis ZJ, De Castella A, Kulkarni J. Transcranial magnetic stimulation in the treatment of depression: a double-blind, placebocontrolled trial. Arch Gen Psychiatry 2003; 60: 1002-1008.

10. George MS, Aston-Jones G. Noninvasive techniques for probing neurocircuitry and treating illness: vagus nerve 
stimulation (VNS), transcranial magnetic stimulation (TMS) and transcranial direct current stimulation (tDCS). Neuropsychopharmacology 2010; 35: 301-316, doi: 10.1038/npp. 2009.87.

11. Brunoni AR, Ferrucci R, Fregni $F$, Boggio PS, Priori A. Transcranial direct current stimulation for the treatment of major depressive disorder: a summary of preclinical, clinical and translational findings. Prog Neuropsychopharmacol Biol Psychiatry 2012; 39: 9-16, doi: 10.1016/j.pnpbp.2012.05.016.

12. Nitsche MA, Cohen LG, Wassermann EM, Priori A, Lang N, Antal A, et al. Transcranial direct current stimulation: State of the art 2008. Brain Stimul 2008; 1: 206-223, doi: 10.1016/ j.brs.2008.06.004.

13. Kalu UG, Sexton CE, Loo CK, Ebmeier KP. Transcranial direct current stimulation in the treatment of major depression: a meta-analysis. Psychol Med 2012; 42: 1791-1800, doi: 10.1017/S0033291711003059.

14. Brunoni $A R$, Valiengo L, Baccaro A, Zanao TA, de Oliveira JF, Goulart A, et al. The sertraline vs. electrical current therapy for treating depression clinical study: results from a factorial, randomized, controlled trial. JAMA Psychiatry 2013; 70: 383-391, doi: 10.1001/2013.jamapsychiatry.32.

15. Gaspar KC, dos Santos A Jr, de Azevedo RC, Mauro ML, Botega NJ. Depression in general hospital inpatients: challenges for consultation-liaison psychiatry. Rev Bras Psiquiatr 2011; 33: 305-307, doi: 10.1590/S1516-44462011000300016.

16. Levenson JL. The American Psychiatric Publishing Textbook of Psychosomatic Medicine: psychiatric care of the medically ill. 2nd edn. Washington: American Psychiatric Pub.; 2011.

17. Musselman DL, Evans DL, Nemeroff CB. The relationship of depression to cardiovascular disease: epidemiology, biology, and treatment. Arch Gen Psychiatry 1998; 55: 580-592, doi: 10.1001/archpsyc.55.7.580.

18. Frasure-Smith $\mathrm{N}$, Lesperance $\mathrm{F}$. Depression and other psychological risks following myocardial infarction. Arch Gen Psychiatry 2003; 60: 627-636, doi: 10.1001/archpsyc. 60.6.627.

19. Carney RM, Blumenthal JA, Stein PK, Watkins L, Catellier $\mathrm{D}$, Berkman LF, et al. Depression, heart rate variability, and acute myocardial infarction. Circulation 2001; 104: 20242028, doi: $10.1161 / \mathrm{hc} 4201.097834$.

20. Welin C, Lappas G, Wilhelmsen L. Independent importance of psychosocial factors for prognosis after myocardial infarction. J Intern Med 2000; 247: 629-639, doi: 10.1046/ j.1365-2796.2000.00694.x.

21. Freedland KE, Lustman PJ, Carney RM, Hong BA. Underdiagnosis of depression in patients with coronary artery disease: the role of nonspecific symptoms. Int J Psychiatry Med 1992; 22: 221-229, doi: 10.2190/YF10-H39R-NY6M-MT1G.

22. Glassman $\mathrm{AH}$, O'Connor CM, Califf RM, Swedberg $\mathrm{K}$, Schwartz P, Bigger JT Jr, et al. Sertraline treatment of major depression in patients with acute $\mathrm{Ml}$ or unstable angina. JAMA 2002; 288: 701-709, doi: 10.1001/jama.288.6.701.

23. Lesperance F, Frasure-Smith N, Koszycki D, Laliberte MA, van Zyl LT, Baker B, et al. Effects of citalopram and interpersonal psychotherapy on depression in patients with coronary artery disease: the Canadian Cardiac Randomized Evaluation of Antidepressant and Psychotherapy Efficacy (CREATE) trial. JAMA 2007; 297: 367-379, doi: 10.1001/ jama.297.4.367.

24. Manolopoulos VG, Ragia G, Alevizopoulos G.
Pharmacokinetic interactions of selective serotonin reuptake inhibitors with other commonly prescribed drugs in the era of pharmacogenomics. Drug Metabol Drug Interact 2012; 27: 19-31, doi: 10.1515/dmdi-2011-0033.

25. Watanabe N, Omori IM, Nakagawa A, Cipriani A, Barbui C, Churchill R, et al. Mirtazapine versus other antidepressive agents for depression. Cochrane Database Syst Rev 2011; CD006528

26. Mbaya P, Alam F, Ashim S, Bennett D. Cardiovascular effects of high dose venlafaxine $\mathrm{XL}$ in patients with major depressive disorder. Hum Psychopharmacol 2007; 22: 129133, doi: 10.1002/hup.834.

27. Sakkas P, Psarros C, Papadimitriou GN, Theleritis CG, Soldatos CR. Repetitive transcranial magnetic stimulation (rTMS) in a patient suffering from comorbid depression and panic disorder following a myocardial infarction. Prog Neuropsychopharmacol Biol Psychiatry 2006; 30: 960-962, doi: 10.1016/j.pnpbp.2006.01.023.

28. Jiang W, Alexander J, Christopher E, Kuchibhatla M, Gaulden LH, Cuffe MS, et al. Relationship of depression to increased risk of mortality and rehospitalization in patients with congestive heart failure. Arch Intern Med 2001; 161: 1849-1856, doi: 10.1001/archinte.161.15.1849.

29. Havranek EP, Ware MG, Lowes BD. Prevalence of depression in congestive heart failure. Am J Cardiol 1999; 84: 348-350, , A9, doi: 10.1016/S0002-9149(99)00293-3.

30. Faris R, Purcell H, Henein MY, Coats AJ. Clinical depression is common and significantly associated with reduced survival in patients with non-ischaemic heart failure. Eur $J$ Heart Fail 2002; 4: 541-551, doi: 10.1016/S13889842(02)00101-0.

31. Joynt KE, Whellan DJ, O'Connor CM. Why is depression bad for the failing heart? A review of the mechanistic relationship between depression and heart failure. J Card Fail 2004; 10: 258-271, doi: 10.1016/j.cardfail.2003.09.008.

32. Norra C, Skobel EC, Arndt M, Schauerte P. High impact of depression in heart failure: early diagnosis and treatment options. Int J Cardiol 2008; 125: 220-231, doi: 10.1016/ j.ijcard.2007.05.020

33. Maurer J, Rebbapragada V, Borson S, Goldstein R, Kunik ME, Yohannes AM, et al. Anxiety and depression in COPD: current understanding, unanswered questions, and research needs. Chest 2008; 134: 43S-56S, doi: 10.1378/ chest.08-0342.

34. van Manen JG, Bindels PJ, Dekker FW, IJzermans CJ, van der Zee JS, Schade E. Risk of depression in patients with chronic obstructive pulmonary disease and its determinants. Thorax 2002; 57: 412-416, doi: 10.1136/thorax.57.5.412.

35. Ng TP, Niti M, Tan WC, Cao Z, Ong KC, Eng P. Depressive symptoms and chronic obstructive pulmonary disease: effect on mortality, hospital readmission, symptom burden, functional status, and quality of life. Arch Intern Med 2007; 167: 60-67, doi: 10.1001/archinte.167.1.60.

36. Yohannes AM, Willgoss TG, Baldwin RC, Connolly MJ. Depression and anxiety in chronic heart failure and chronic obstructive pulmonary disease: prevalence, relevance, clinical implications and management principles. Int $\mathrm{J}$ Geriatr Psychiatry 2010; 25: 1209-1221, doi: 10.1002/ gps.2463.

37. Lasser K, Boyd JW, Woolhandler S, Himmelstein DU, McCormick D, Bor DH. Smoking and mental illness: A 
population-based prevalence study. JAMA 2000; 284: 26062610, doi: 10.1001/jama.284.20.2606.

38. Schneider C, Jick SS, Bothner U, Meier CR. COPD and the risk of depression. Chest 2010; 137: 341-347, doi: 10.1378/ chest.09-0614.

39. Laurin C, Moullec G, Bacon SL, Lavoie KL. The impact of psychological distress on exacerbation rates in COPD. Ther Adv Respir Dis 2011; 5: 3-18, doi: 10.1177/1753465810382818.

40. Smith J, Albert P, Bertella E, Lester J, Jack S, Calverley P. Qualitative aspects of breathlessness in health and disease. Thorax 2009; 64: 713-718, doi: 10.1136/thx.2008.104869.

41. Cafarella PA, Effing TW, Usmani ZA, Frith PA. Treatments for anxiety and depression in patients with chronic obstructive pulmonary disease: a literature review. Respirology 2012; 17: 627-638, doi: 10.1111/j.1440-1843.2012.02148.x.

42. Boyd CA, Benarroch-Gampel J, Sheffield KM, Han Y, Kuo YF, Riall TS. The effect of depression on stage at diagnosis, treatment, and survival in pancreatic adenocarcinoma. Surgery 2012; 152: 403-413, doi: 10.1016/j.surg.2012.06.010.

43. Frazzetto $P$, Vacante $M$, Malaguarnera M, Vinci E, Catalano F, Cataudella E, et al. Depression in older breast cancer survivors. BMC Surg 2012; 12 (Suppl 1): S14, doi: 10.1186/ 1471-2482-12-S1-S14.

44. Carney CP, Jones L, Woolson RF, Noyes R Jr, Doebbeling $B N$. Relationship between depression and pancreatic cancer in the general population. Psychosom Med 2003; 65: 884-888, doi: 10.1097/01.PSY.0000088588.23348.D5.

45. Jia L, Jiang SM, Shang YY, Huang YX, Li YJ, Xie DR, et al. Investigation of the incidence of pancreatic cancer-related depression and its relationship with the quality of life of patients. Digestion 2010; 82: 4-9, doi: 10.1159/000253864.

46. Mayr M, Schmid RM. Pancreatic cancer and depression: myth and truth. BMC Cancer 2010; 10: 569, doi: 10.1186/ 1471-2407-10-569.

47. Henry NL, Stearns V, Flockhart DA, Hayes DF, Riba M. Drug interactions and pharmacogenomics in the treatment of breast cancer and depression. Am J Psychiatry 2008; 165: 1251-1255, doi: 10.1176/appi.ajp.2008.08040482.

48. Desmarais JE, Looper KJ. Interactions between tamoxifen and antidepressants via cytochrome P450 2D6. J Clin Psychiatry 2009; 70: 1688-1697, doi: 10.4088/JCP. 08r04856blu.

49. Kouwenhoven SE, Kirkevold M, Engedal K, Kim HS. Depression in acute stroke: prevalence, dominant symptoms and associated factors. A systematic literature review. Disabil Rehabil 2011; 33: 539-556, doi: 10.3109/09638288. 2010.505997

50. Robinson RG, Schultz SK, Castillo C, Kopel T, Kosier JT, Newman RM, et al. Nortriptyline versus fluoxetine in the treatment of depression and in short-term recovery after stroke: a placebo-controlled, double-blind study. Am J Psychiatry 2000; 157: 351-359, doi: 10.1176/appi.ajp.157. 3.351.

51. Andersen G, Vestergaard K, Riis J, Lauritzen L. Incidence of post-stroke depression during the first year in a large unselected stroke population determined using a valid standardized rating scale. Acta Psychiatr Scand 1994; 90: 190-195, doi: 10.1111/j.1600-0447.1994.tb01576.x.

52. Kim BR, Kim DY, Chun MH, Yi JH, Kwon JS. Effect of repetitive transcranial magnetic stimulation on cognition and mood in stroke patients: a double-blind, sham-controlled trial. Am J Phys Med Rehabil 2010; 89: 362-368, doi: 10.1097/PHM.0b013e3181d8a5b1.

53. Jorge RE, Robinson RG, Tateno A, Narushima K, Acion L, Moser D, et al. Repetitive transcranial magnetic stimulation as treatment of poststroke depression: a preliminary study. Biol Psychiatry 2004; 55: 398-405, doi: 10.1016/j.biopsych.2003.08.017.

54. Bueno VF, Brunoni AR, Boggio PS, Bensenor IM, Fregni F. Mood and cognitive effects of transcranial direct current stimulation in post-stroke depression. Neurocase 2011; 17: 318-322, doi: 10.1080/13554794.2010.509319.

55. Mendez MF, Cummings JL, Benson DF. Depression in epilepsy. Significance and phenomenology. Arch Neurol 1986; 43: 766-770, doi: 10.1001/archneur.1986. 00520080014012.

56. Kanner AM, Soto A, Gross-Kanner H. Prevalence and clinical characteristics of postictal psychiatric symptoms in partial epilepsy. Neurology 2004; 62: 708-713, doi: 10.1212/ 01.WNL.0000113763.11862.26.

57. Barraclough BM. The suicide rate of epilepsy. Acta Psychiatr Scand 1987; 76: 339-345, doi: 10.1111/j.16000447.1987.tb05616.x.

58. Currie S, Heathfield KW, Henson RA, Scott DF. Clinical course and prognosis of temporal lobe epilepsy. A survey of 666 patients. Brain 1971; 94: 173-190, doi: 10.1093/brain/ 94.1.173

59. Rosenstein DL, Nelson JC, Jacobs SC. Seizures associated with antidepressants: a review. J Clin Psychiatry 1993; 54: 289-299.

60. Burn DJ. Beyond the iron mask: towards better recognition and treatment of depression associated with Parkinson's disease. Mov Disord 2002; 17: 445-454, doi: 10.1002/mds.10114.

61. Aiken CB. Pramipexole in psychiatry: a systematic review of the literature. J Clin Psychiatry 2007; 68: 1230-1236, doi: 10.4088/JCP.v68n0810.

62. Raudino F. Non motor off in Parkinson's disease. Acta Neurol Scand 2001; 104: 312-315, doi: 10.1034/j.16000404.2001.00357.x.

63. Weintraub D, Stern MB. Psychiatric complications in Parkinson disease. Am J Geriatr Psychiatry 2005; 13: 844-851.

64. Epstein CM, Evatt ML, Funk A, Girard-Siqueira L, Lupei N, Slaughter $\mathrm{L}$, et al. An open study of repetitive transcranial magnetic stimulation in treatment-resistant depression with Parkinson's disease. Clin Neurophysiol 2007; 118: 21892194, doi: 10.1016/j.clinph.2007.07.010.

65. Dragasevic N, Potrebic A, Damjanovic A, Stefanova E, Kostic VS. Therapeutic efficacy of bilateral prefrontal slow repetitive transcranial magnetic stimulation in depressed patients with Parkinson's disease: an open study. Mov Disord 2002; 17: 528-532, doi: 10.1002/mds.10109.

66. Kormos TC. Efficacy of rTMS in the treatment of co-morbid anxiety in depressed patients with Parkinson's disease. Mov Disord 2007; 22: 1836, doi: 10.1002/mds.21613.

67. Fregni F, Santos CM, Myczkowski ML, Rigolino R, GallucciNeto J, Barbosa ER, et al. Repetitive transcranial magnetic stimulation is as effective as fluoxetine in the treatment of depression in patients with Parkinson's disease. J Neurol Neurosurg Psychiatry 2004; 75: 1171-1174, doi: 10.1136/ jnnp.2003.027060.

68. Pal E, Nagy F, Aschermann Z, Balazs E, Kovacs N. 
The impact of left prefrontal repetitive transcranial magnetic stimulation on depression in Parkinson's disease: a randomized, double-blind, placebo-controlled study. Mov Disord 2010; 25: 2311-2317, doi: 10.1002/mds.23270.

69. Bing EG, Burnam MA, Longshore D, Fleishman JA, Sherbourne CD, London AS, et al. Psychiatric disorders and drug use among human immunodeficiency virusinfected adults in the United States. Arch Gen Psychiatry 2001; 58: 721-728, doi: 10.1001/archpsyc.58.8.721.

70. Irwin MR, Miller AH. Depressive disorders and immunity: 20 years of progress and discovery. Brain Behav Immun 2007; 21: 374-383, doi: 10.1016/j.bbi.2007.01.010.

71. Evans DL, Ten Have TR, Douglas SD, Gettes DR, Morrison $M$, Chiappini MS, et al. Association of depression with viral load, CD8 T lymphocytes, and natural killer cells in women with HIV infection. Am J Psychiatry 2002; 159: 1752-1759, doi: 10.1176/appi.ajp.159.10.1752.

72. Deeks SG, Volberding PA. HIV-1 protease inhibitors. AIDS Clin Rev 1997; 145-185.

73. Knotkova H, Rosedale M, Strauss SM, Horne J, Soto E, Cruciani RA, et al. Using Transcranial Direct Current Stimulation to Treat Depression in HIV-Infected Persons: The Outcomes of a Feasibility Study. Front Psychiatry 2012; 3: 59, doi: 10.3389/fpsyt.2012.00059.

74. Campagne DM. The obstetrician and depression during pregnancy. Eur J Obstet Gynecol Reprod Biol 2004; 116: 125-130, doi: 10.1016/j.ejogrb.2003.11.028.

75. Petersen I, Gilbert R, Evans S, Nazareth I. Selective serotonin reuptake inhibitors and risk for major congenital anomalies. Obstet Gynecol 2012; 119: 182-183, doi: 10.1097/AOG.0b013e31823f29ee.

76. Pedersen LH, Henriksen TB, Vestergaard M, Olsen J, Bech $\mathrm{BH}$. Selective serotonin reuptake inhibitors in pregnancy and congenital malformations: population based cohort study. BMJ 2009; 339: b3569, doi: 10.1136/bmj.b3569.

77. Oyebode F, Rastogi A, Berrisford G, Coccia F. Psychotropics in pregnancy: safety and other considerations. Pharmacol Ther 2012; 135: 71-77, doi: 10.1016/ j.pharmthera.2012.03.008.

78. Kim DR, Epperson N, Pare E, Gonzalez JM, Parry S, Thase $\mathrm{ME}$, et al. An open label pilot study of transcranial magnetic stimulation for pregnant women with major depressive disorder. J Womens Health 2011; 20: 255-261, doi: 10.1089/jwh.2010.2353.

79. Zhang X, Liu K, Sun J, Zheng Z. Safety and feasibility of repetitive transcranial magnetic stimulation (rTMS) as a treatment for major depression during pregnancy. Arch Womens Ment Health 2010; 13: 369-370, doi: 10.1007/ s00737-010-0163-5.

80. Tan O, Tarhan N, Coban A, Baripoglu SK, Guducu F, Izgi $\mathrm{HB}$, et al. Antidepressant effect of 58 sessions of rTMS in a pregnant woman with recurrent major depressive disorder: A case report. Prim Care Companion J Clin Psychiatry 2008; 10: 69-71, doi: 10.4088/PCC.v10n0113a.

81. Nahas Z, Bohning DE, Molloy MA, Oustz JA, Risch SC, George MS. Safety and feasibility of repetitive transcranial magnetic stimulation in the treatment of anxious depression in pregnancy: a case report. J Clin Psychiatry 1999; 60: 5052, doi: 10.4088/JCP.v60n0111.

82. Garcia KS, Flynn P, Pierce KJ, Caudle M. Repetitive transcranial magnetic stimulation treats postpartum depression. Brain Stimul 2010; 3: 36-41, doi: 10.1016/j.brs.2009. 06.001.

83. Dodick DW, Schembri CT, Helmuth M, Aurora SK Transcranial magnetic stimulation for migraine: a safety review. Headache 2010; 50: 1153-1163, doi: 10.1111/ j.1526-4610.2010.01697.x.

84. Rossi S, Hallett M, Rossini PM, Pascual-Leone A. Safety, ethical considerations, and application guidelines for the use of transcranial magnetic stimulation in clinical practice and research. Clin Neurophysiol 2009; 120: 2008-2039, doi: 10.1016/j.clinph.2009.08.016.

85. Slotema CW, Blom JD, Hoek HW, Sommer IE. Should we expand the toolbox of psychiatric treatment methods to include Repetitive Transcranial Magnetic Stimulation (rTMS)? A meta-analysis of the efficacy of rTMS in psychiatric disorders. J Clin Psychiatry 2010; 71: 873-884, doi: 10.4088/JCP.08m04872gre.

86. Pascual-Leone A, Rubio B, Pallardo F, Catala MD. Rapidrate transcranial magnetic stimulation of left dorsolateral prefrontal cortex in drug-resistant depression. Lancet 1996; 348: 233-237, doi: 10.1016/S0140-6736(96)01219-6.

87. Zaghi $S$, Heine N, Fregni $F$. Brain stimulation for the treatment of pain: A review of costs, clinical effects, and mechanisms of treatment for three different central neuromodulatory approaches. J Pain Manag 2009; 2: 339-352. 